\title{
Acceleration of granulation tissue using myrmecodiapendens extract induction during wound healing tooth extraction process (experimental research on caviacobaya)
}

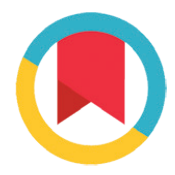

CrossMark

\author{
Efa Ismardianita, Wenny Rosalina
}

\begin{abstract}
Objective: To identify the effect of myrmecodiapendens extract 20\% on granulation tissue post-tooth extraction.

Material and Methods: Twenty-four caviacobaya divided into two groups: the control group and treatment group. Lower left incisor tooth subjects were extracted and the entire socket filled with CMC $0.5 \%$ in the control group and myrmecodiapendens extract $20 \%$ in the treatment group, 0.1 CC in each subject. On days $3,7,14$, and 21 subjects were determined, subsequently, socket tissues were stained with Haematoxylin Eosin (HE) technique. Angiogenesis, fibroblast, and macrophage were used to evaluated

granulation tissue on wound healing post-tooth extraction. Data were analyzed with the Kruskal-Wallis test to see differences between the control group and treatment group with a level of significant $p<0.05$.

Results: This study indicates significant differences in angiogenesis, fibroblast, and macrophage between control group and treatment group $(p<0.05)$.

Conclusion: This study confirmed the effect of myrmecodiapendens extract 20\% increase angiogenesis, fibroblast, and macrophage, which is can improve wound healing process post-tooth extraction.
\end{abstract}

Department of Oral and Maxillofacial Surgery, Faculty of Dentistry, University of Baiturrahmah, Padang, Indonesia
${ }^{*}$ Correspondence to:

Efa Ismardianita, Department of Oral and Maxillofacial Surgery, Faculty of Dentistry, University of Baiturrahmah, Padang, Indonesia efa_ismardianita@yahoo.co.id

Received: 1 April 2020

Revised: 26 May 2020

Accepted: 14 July 2020

Available Online: 1 August 2020

Keywords: Myrmecodiapendens extract, Granulation tissue, Wound healing

Cite this Article: Ismardianita E, Rosalina W. 2020. Acceleration of granulation tissue using myrmecodiapendens extract induction during wound healing tooth extraction process (experimental research on caviacobaya). Journal of Dentomaxillofacial Science 5(2): 124-128. D0l: 10.15562/jdmfs.v5i2.1071

\section{Introduction}

After tooth extraction, patients often complain of various complications, such as pain, swelling, impaired speech function, and mastication function. ${ }^{1}$ To reduce the risk of complications, dentists give medications. The chemical-based medication has advantages besides that they also have some detrimental effects. ${ }^{2}$ Wound healing consists of a variety of complex biological processes, involving all tissues to complete the process of wound healing, characterized by the formation of granulation tissue consisting of macrophages, fibroblasts, and new blood vessels (angiogenesis). ${ }^{3}$

Wound healing consists of the inflammatory, proliferation, and remodeling phases. Intervention in the process of wound healing is usually done in the inflammatory phase. In the inflammatory phase of macrophages secreting proinflammatory cytokines such as Tumor Necrosis Factor $\alpha$ (TNF- $\alpha$ ), Transforming Growth Factor $\beta$ (TGF- $\beta$ ), Interleukin 1 (IL-1), Interleukin 6 (IL-6), Interleukin 8 (IL-8), proteinase (collagenase enzyme), Metalloproteinase Matrix (MMPS) and Prostaglandin E2 (PGE2). These cytokines stimulate inflammatory cells (neutrophils, macrophages, and osteoclasts) for migration to the injured area, phagocytosis debris, foreign bodies, and necrotic tissue. Besides, macrophages also secrete growth factors including Transforming Growth Factor- $\beta 1$ (TGF- $\beta$ ), Bone Morphogenic Proteins (BMP-2, -5, -7), and Fibroblast Growth Factor (FGF), Platelet-Derived Growth Factor (PDGF), and Insulin-Like Growth Factor (IGF). These growth factors play a role in recruiting, migrating, and proliferating mesenchymal cells into angioblasts, fibroblasts, and osteoblasts. ${ }^{4,5}$

Angiogenesis (formation of new blood vessels) is important in wound healing to supply nutrients and oxygen to tissues and is important for cell metabolism. Angiogenesis begins on the 3rd day of the post-injury. On the 4th day the number increased, the peak was on the 7 th day and the number began to decrease on the 10 day. ${ }^{6}$ Fibroblasts produce type 1 collagen, which is collagen which is the main component of the extracellular matrix. Some fibroblasts differentiate into osteoblasts. These cells form alveolar bone. Fibroblasts appear in the wound area after the third day, increasing on the seventh day and peaking on the fourteenth day. ${ }^{7}$

Indonesiais a mega-biodiversity country with very high plant diversity, Indonesia's tropical forests have a variety of biodiversity of more than 2.039 species 
of medicinal plants. ${ }^{8}$ Myrmecodiapendens which is commonly called the SarangSemut is a plant originating from Papua, Indonesia. Myrmecodiapendensis often used by residents as a medicinal plant to cure various diseases, such as cancer, tumors, diarrhea, arthritis and fever., ${ }^{910}$ Phytochemical tests show that Myrmecodiapendens contains flavonoids, saponins, tannins, tocopherols, and alkaloids so that it has effects as antibacterial, anti-inflammatory, antioxidant. ${ }^{11}$

Based on the above background the researcher wants to identify the effectiveness of the $20 \%$ Myrmecodiapendens tuber extract against granulation tissue on the $3 \mathrm{rd}, 7 \mathrm{th}, 14 \mathrm{th}$, and 21 st day after tooth extraction.

\section{Material and Methods}

Type of research: is a true laboratory experimental design with a post-test only control group design. The study population was male guinea pig (Caviacobaya) weighing 250-400 grams, aged 6-8 weeks. The sample is determined by the Federer formula: the total sample of each group is 3 guinea pigs. Independent variable: Myrmecodiapendens extract $20 \%$ and the dependent variable: granulation tissue (macrophages, fibroblasts, and angiogenesis).

Myrmecodiapendens was collected from Ayawasi Village, Sorong Regency, Papua Indonesia. Plant identification was carried out at the Herbarium Laboratory of Andalas University, Padang. Myrmecodiapendens extract was made at the Chemistry Laboratory of Padjajaran University, Bandung. Tooth extraction and observation were carried out in LPPT IV and Anatomy Pathology Laboratory Gadjah Mada University. The study was declared ethical by the Commission on the Code of Ethics for the Research of the Faculty of Medicine at Andalas University (Certificate of Passing the Ethics Review No: 011 / KEP / FK / 2016). This research was carried out from October 2018 to April 2019.

The research material used in this research were 12 male guinea pigs, anesthetics, Ant Nest (Myrmecodiapendens), 70\% ethanol, CMC 0.5\%, ketamine $10 \%$, xylazine $2 \%, 10 \%$ formalin buffer, Plank-Rychlo's solution, ethanol alcohol, xylol, nitric acid, paraffin, Haematoxylin Eosin.

Myrmecodiapendens bulbs are peeled, thinly sliced $(3-5 \mathrm{~mm})$, dried in an oven $\left(50^{\circ} \mathrm{C}\right)$ until dry and easy to break, then blended to a coarse powder. 250 grams of Myrmecodiapendens powder was mixed with $70 \%$ ethanol (ratio 1:5). Maceration was carried out by shaking in the first 6 hours followed by cooling for 18 hours. Maceration is done repeatedly until the filtrate changes color, then evaporated with a rotary evaporator, then put into the oven $\left(50^{\circ} \mathrm{C}\right)$ until all the water is evaporated and the extract is completely dry. Experimental animals were anesthetized intramuscularly with Ketamine $80 \mathrm{mg} / \mathrm{kgBB}$ and Xylazine $160 \mathrm{mg} / \mathrm{kgBB}$ (ratio 1:2), after the guinea pig fell asleep, the extraction of the lower-left incisors was extracted, into the socket, the control group was applied 0.5\% CMC and the treatment group was given a Myrmecodiapendens extract $20 \%$, $0.1 \mathrm{cc}$ each. On the 3rd, 7th, 14th and 21st day of the experimental animals were determined, socket tissue was taken and histological preparations made with Haematoxylin Eosin staining. Granulation tissue evaluation is performed by looking at angiogenesis, fibroblasts and macrophages.

Angiogenesis assessment based on scores: $0=$ no blood vessels, $1=$ few blood vessels, $2=$ number of medium (diffuse) blood vessels, $3=$ number of large (massive) blood vessels, $4=$ number of very large blood vessels (90-100\% field of view). Fibroblasts are assessed based on a score: $0=$ no fibroblasts, $1=$ low number of fibroblasts $(<10 \%$ field of view), $2=$ number of medium fibroblasts $(10-50 \%$ of field of view), $3=$ number of fibroblasts densely $(50-90 \%$ of field of view) ), $4=$ number of fibroblasts very tight (90-100\% field of view). Macrophages are calculated by summing the average field of view. Data were analyzed by the Kruskal-Wallis test to see differences between groups with a significant level of $\mathrm{p}<0.05$.

\section{Results}

The results of observing granulation tissue in the control group and the treatment group showed an average of angiogenesis, fibroblasts, and macrophages on days 3, 7, 14, and 21 seen in Graphs 1, 2 , and 3 .

Figure 1 shows that on the 3rd day the angiogenesis density in both groups increased, the peak

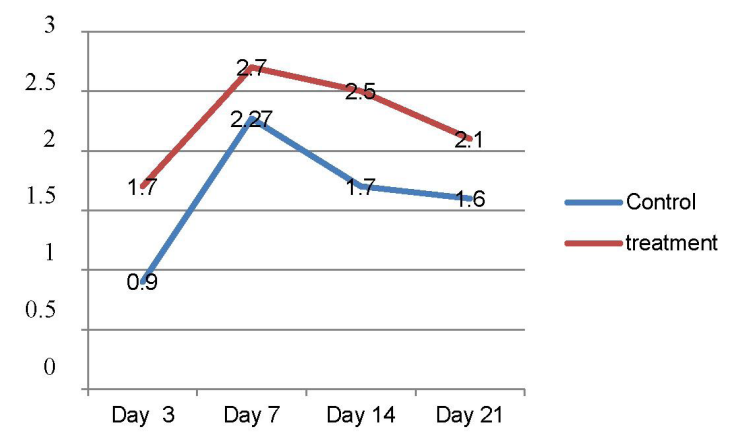

Caption:

* $=$ angiogenesis

$\mathrm{f}=$ fibroblasts

$\mathrm{m}=$ macrophage

Figure 1 Average angiogenesis on days 3, 7, 14, and 21 after tooth extraction 
was on the 7th day and decreased slowly until the 21 st day. The density of the angiogenesis treatment group was higher compared to the control group.

Figure 2 shows that on the 3rd day the density of fibroblasts in both groups increased, the peak was on the 7th day and decreased until the 21st day. The amount of fibroblast density in the treatment group was higher than in the control group.

Figure 3 shows that on the 3rd day macrophages in both groups increased, the peak was on the 7th day and decreased until the 21 st day. The number

\section{Table 1 Kruskal-Wallis test of control and treatment angiogenesis} on days $3,7,14$ and 21

\begin{tabular}{llccc}
\hline Day & Control/Treatment & N & Mean Rank & Sig. \\
\hline 3 & CMC & 3 & 2.00 & \\
& Myrmecodiapendens 20\% & 3 & 8.67 & \\
7 & CMC & 3 & 7.00 & \\
& Myrmecodia pendens 20\% & 3 & 21.50 & 0.004 \\
\multirow{2}{*}{21} & CMC & 3 & 17.17 & \\
& Myrmecodiapendens 20\% & 3 & 20.67 & \\
& CMC & 3 & 8.67 & \\
& Myrmecodiapendens 20\% & 3 & 14.33 & \\
\hline
\end{tabular}

Table 2 Kruskal-Wallis of control and treatment fibroblast on days $3,7,14$ and 21

\begin{tabular}{llccc}
\hline Day & Control/Treatment & N & Mean Rank & Sig. \\
\hline 3 & CMC & 3 & 2.00 & \\
& Myrmecodiapendens20\% & 3 & 6.50 & \\
7 & CMC & 3 & 6.50 & \\
& Myrmecodiapendens20\% & 3 & 23.00 & 0.002 \\
\multirow{2}{*}{21} & CMC & 3 & 16.67 & \\
& Myrmecodiapendens20\% & 3 & 19.50 & \\
& CMC & 3 & 11.50 & \\
& Myrmecodiapendens20\% & 3 & 14.33 & \\
\hline
\end{tabular}

Table 3 Kruskal-Wallis test of macrophages of control and treatment groups on day 3, 7, 14 and 21

\begin{tabular}{lllcl}
\hline Day & Control/Treatment & N & Mean rank & Sig. \\
\hline 3 & CMC & 3 & 3.00 & \\
& Myrmecodiapendens20\% & 3 & 9.00 & \\
7 & CMC & 3 & 10.00 & \\
\multirow{2}{*}{14} & Myrmecodiapendens20\% & 3 & 23.00 & \multirow{2}{*}{0.003} \\
\multirow{2}{*}{21} & CMC & 3 & 15.33 & \\
& CMrmecodiapendens20\% & 3 & 20.00 & \\
& Myrmecodiapendens20\% & 3 & 4.00 & \\
\hline
\end{tabular}

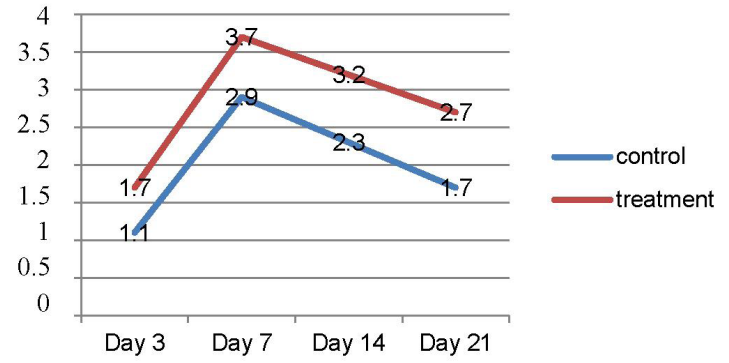

Figure 2 Mean fibroblasts on days 3, 7, 14, and 21 after tooth extraction

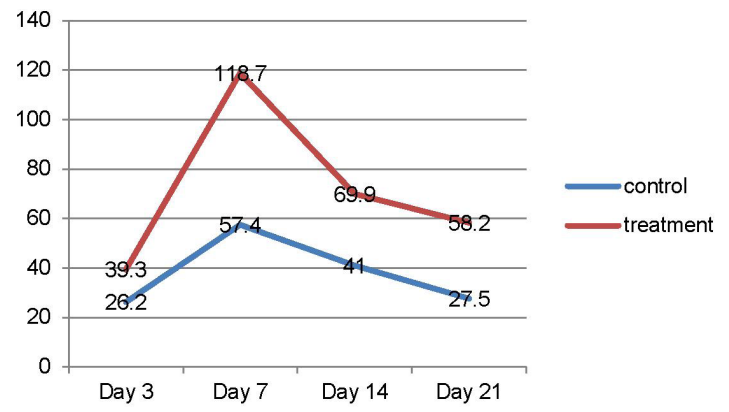

Figure 3 Mean macrophages on days 3, 7, 14, and 21 after tooth extraction
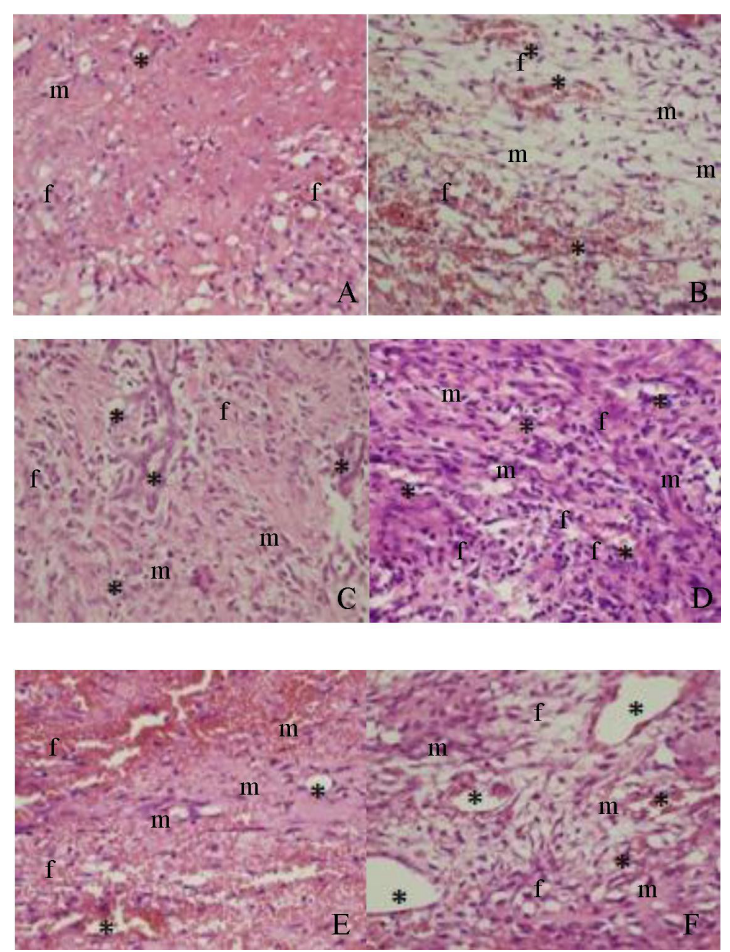

Figure 4 Histopathological features of granulation tissue (angiogenesis, macrophages, and fibroblasts) A. The 3rd days in the control group, B. The treatment group, C. The 7th days in the control group, D. The treatment group, E. The 14th days in the control group, F. The treatment group 
of macrophages in the treatment group was higher than in the control group.

The data obtained was performed by the Kruskal-Wallis test and obtained a significance value $(\mathrm{p}<0.05)$ in all groups of observation days.

Kruskal-Wallis test results between the control group and the treatment group showed a significant difference on days $3,7,14$, and 21 ( $\mathrm{p}<0.05)$.

\section{Discussion}

Phytochemical tests show that myrmecodiapendenscontains flavonoids, saponins, tannins, tocopherols, and alkaloids. ${ }^{11}$ This plant affects antibacterial, anti-inflammatory, and antioxidant. Wound healing can be accelerated by administering myrmecodiapendens extract.

In this study, the observation of the amount of granulation tissue in the treatment group was higher than the control group. This finding is consistent with the theory that granulation tissue consisting of angiogenesis, fibroblasts, and macrophages began to form from day 3 to day 14, and the peak occurred on day $7 .{ }^{12}$ Granulation tissue was higher in the treatment group than in the control group, it could be due to the active substance content in the myrmecodiapendens extract.

Anti-inflammatory flavonoids suppress M1 activation by activating Nuclear Factor-kappa $\beta$ (NF-k $\beta$ ) transcription factors, thereby suppressing stimulation of pro-inflammatory cytokines such as IL-1, IL-6, and TNF- $\alpha$ so that the inflammatory phase is shorter. In addition, macrophages activate M2 which will stimulate the secretion of IL-10 and growth factors such as VEGF, FGF, BMP-2, and TGF- $\beta 1$ which are important for bone healing, with increased expression of growth factors, will stimulate increased angioblast cell proliferation, fibroblasts, osteoblasts which are important for bone healing, with increased expression of growth factors, will stimulate increased angioblast cell proliferation, fibroblasts, osteoblasts which are important for bone healing will form extracellular bone matrix. ${ }^{13}$

Flavonoids are powerful antioxidants that can reduce peroxidase, increase the speed of epithelialization, and antimicrobials. Decreased lipid peroxidase by flavonoids will prevent necrosis, improve vascularity, and increase the viability of collagen fibers. ${ }^{14}$ Flavonoids activate $\mathrm{T}$ cells into TH1, TH2, and TH3. TH3 cells produce Transforming Growth Factor- $\beta$ (TGF- $\beta$ ) which will stimulate fibroblast proliferation. Fibroblasts produce type 1 collagen, which is collagen which is the main component of the extracellular matrix. Some fibroblasts differentiate into osteoblasts, forming bone. ${ }^{14,15}$
Flavonoids and tannins play a role in the regulation of VEGF transcription and translation, helping to re-epithelialize and stimulate angiogenesis which will restore the perfusion of nutrients and oxygen. ${ }^{16}$ The new blood vessels that are formed the wound healing process will take place faster.

Saponins as antimicrobials, increase the permeability of bacterial cell membranes, consequently, bacteria become lysis. ${ }^{17}$ Saponins can also increase the ability of TGF- $\beta$ receptors required by fibroblasts to synthesize collagen. ${ }^{14,18}$ Tocopherol in myrmecodiapendens functions as an antioxidant that can accelerate wound healing. ${ }^{19}$ Tocopherol stimulates the production of cyclic adenosine monophosphate (cAMP) related to the immunomodulatory effect by modulating the inflammatory response in various types of immune cells including macrophages.

Alkaloids have anti-inflammatory effects and inhibit the growth of bacteria which can modulate the inflammatory phase in the wound healing process. Alkaloids help the wound healing process by deposition of collagen in angiogenesis and reduce the number of bacteria in the wound area.

\section{Conclusion}

There is a difference in the density of granulation tissue (angiogenesis, fibroblasts, and macrophages) in the post-tooth extraction socket between the control group and the treatment group given myrmecodiapendens extract $20 \%$.

\section{Acknowledgment}

The authors would like to express our appreciation to Hamdy Lisfrizal for statistical analysis.

\section{Conflict of Interest}

The authors report no conflict of interest.

\section{References}

1. Kareem JJ. Post operative complications associated with non-surgical tooth extraction. MDJ 2008;5: 104-113.

2. Schmidlin PR, Imfeld P, Sahrmann A, et al. Effect of shorttime povidone-iodine application on osteoblast proliferation and differentiation. Open Dentist J 2009;3: 208-212.

3. Politis C, Joseph S, Reinhilde J, et al. Wound healing problems in the mouth. Front Physiol 2016;7: 1-13.

4. Rowan MP, Cancio LC, Elster EA, et al. Burn wound healing and treatment: review and advancements. Critical Car 2015;19: 143.

5. Honnegowda TM, Pramod K, Echalarasa GPU, et al. Role of angiogenesis in acute and chronic wound healing. Plast Aesthet Res 2015;2: 243-249.

6. Tonnesen MG, Feng X, Clark RAF. Angiogenesis in wound helaing. New York: Department of Dermatology, Health Sciences Center; 2000. p. 40-46. 
7. Supriatno DR. antitumor activity of papuas's myrmecodiapendens in human oral tongue squamous cell carcinoma cell line through induction of cyclindependent kinase inhibitor p27Kp1 and suppression of cyclin E. J of Cancer Res and Ther 2014;2: 48-53.

8. Soeksmanto A, Subroto M, Wijaya H, et al. Anticancer activity test for extracts of sarangsemut (myrmecodiapendens) to HeLa and MCM-B2 cells. Pak J Biol Sci 2010;13: 148-151.

9. Roslizawaty, Budiman $\mathrm{H}$, Laila $\mathrm{H}$, et al. The effect ethanolic extraxt of ant plant (myrmecodia sp.) on histopatological changes in the kidney of hiperurisemic male mice (mus musculus). J Medika Veterinaria 2013;7: 116-120.

10. Gonzales AC, Costa TF, Andrade ZA, et al. Wound healing-a literature review. An Bras Dermatol 2016;91: 614-620.

11. Hashemi SA, Madani SA, Abediankenari S. The Review on properties of Aloe vera in healing of cutaneouswounds. Biomed Res Int 2015: 1-6.

12. Agarwal PK, Singh A, Gaurav K, et al. Evaluation of wound healing activity of extract plantae banana (M. sapientum var. paradisiaca) in rats. Indian J Exp Biol 2009;47: 332-340.

13. Kresnoaadi $U$. The increasing of fibroblast growth factor 2, osteocalsin and osteoblast due to the induction of combination of Aloe veraand 2\% xenograft concelous bovine. Dent J 2012;45: 228-232.
14. Silva SS, EG Popa, ME Gomes, et al. An Investigation of the potential application of chitosan/aloe-based membranes for regenerative medicin. ActaBiomat. 2013;9: 1-5.

15. Diegelmann RF, Evans MC. Wound healing: am overview of acute, fibrotic and delayed healing. Front Biosci 2004;9: 283-289.

16. Mukherjee A, Roychowdhury B. The in vitro propagation of aloe vera sp. TIG Res J 2008;1: 116-119.

17. Sobazo SE, Soto PG, Valdes RC, et al. Applied biological and physicochemical activity of isoquinoline alkaloids: oxoisoaporphine and boldine. Molec 2012;17: 10958-10970.

18. Fetse JP, James OK, Evans D, et al. Wound healing activity of total alkaloidal extract of the root bark of Aistonia boonei (Apocynacea). British J Pharm Res Sci Dom 2014;2: 2642-2652.

19. Ismardianita E, Widyawati, Elianora D, et al. The effectiveness methanol extract clausena excavate on number of fibroblast and densityof collagen fibers after tooth extraction. J Dentomaxillofac Sci 2019;4: 170-175.

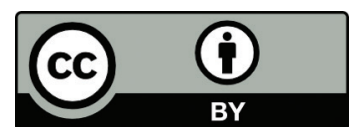

This work is licensed under a Creative Commons Attribution 